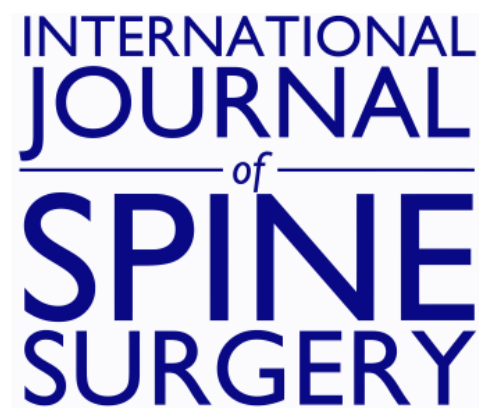

\title{
Factors Affecting Utilization of Steroid Injections in the Treatment of Lumbosacral Degenerative Conditions in the United States
}

SOHRAB S. VIRK, FRANK M. PHILLIPS and SAFDAR N. KHAN

Int J Spine Surg 2018, 12 (2) 139-148

doi: https://doi.org/10.14444/5021

http://ijssurgery.com/content/12/2/139

This information is current as of April 25, 2023.

Email Alerts Receive free email-alerts when new articles cite this article. Sign up at:

http://ijssurgery.com/alerts

The International Journal of Spine Surgery

2397 Waterbury Circle, Suite 1,

Aurora, IL 60504, Phone: +1-630-375-1432 


\title{
Factors Affecting Utilization of Steroid Injections in the Treatment of Lumbosacral Degenerative Conditions in the United States
}

\author{
SOHRAB S. VIRK, MD, MBA, ${ }^{1}$ FRANK M. PHILLIPS, MD, ${ }^{2}$ SAFDAR N. KHAN, MD ${ }^{1}$ \\ ${ }^{1}$ Department of Orthopaedics, Wexner Medical Center, The Ohio State University, Columbus, Ohio, and ${ }^{2}$ Midwest Orthopaedics at Rush, Rush University \\ Medical Center, Chicago, Illinois
}

\begin{abstract}
Background: Lumbar degenerative conditions are an extremely common set of diagnoses with a large spectrum of treatment options. Epidural steroid injections (ESI) are widely used but have come under increased scrutiny as we move toward a value-based model of health care. We assessed current utilization of epidural steroid injections, changes in utilization over time, and the influence of payer type and geographic region within the United States on their utilization. In addition, we analyzed the relationship between ESIs and surgical rates across states.

Methods: The Medicare 5\% national sample administrative database (SAF5) and a large national database from a commercial health care company (HORTHO) were used to catalog clinical data for patients with lumbar degenerative conditions. Specific queries into the rate of ESIs and lumbar surgery were also performed within this group.

Results: There were 4108121 patients found between 2005 and 2015 in the SAF5 and HORTHO databases carrying a diagnosis related to lumbar degenerative conditions. The overall yearly injection rates for patients with lumbar degenerative conditions ranged from $9.84 \%$ to $10.18 \%$. In patients older than 65 , the rate of ESI was higher for Medicare as compared with private payer insurance $(16.27 \%$ versus $14.14 \%, P<.001)$. There was a higher rate of ESI for patients who eventually underwent surgery in the Medicare group as compared with the commercial group (55.30\% versus $40.40 \%, P<.001)$. There was a positive correlation between rates of ESI with the rate of surgery between states.

Conclusions: There is considerable variation in treatment of lumbar degenerative conditions with ESI based on payer type. There was increased utilization of lumbar ESI between 2007 and 2012, although this change was less than $0.5 \%$. The data also suggest a positive correlation between rates of ESIs and surgical intervention across states. This points to areas in the country with high utilization of both ESI and surgery in the treatment of lumbar degenerative conditions.
\end{abstract}

Level of Evidence: III, economic and decision analysis

Lumbar Spine

Keywords: lumbar spine, degenerative conditions, epidural steroid injection, resource allocation

\section{INTRODUCTION}

Epidural steroid injections (ESIs) are widely used in the treatment of symptomatic lumbar degenerative conditions. These are considered "conservative" modalities in the treatment spectrum and are often used to treat symptoms in an attempt to avoid or at least delay surgical intervention. Conflicting results of the efficacy of ESIs for the treatment of common lumbar conditions have been published. ${ }^{1-4}$ Despite questions regarding their efficacy, ESIs are still frequently performed. To date there have been few publications assessing the factors that influence the utilization of ESIs and assessing whether their use influences the rate of lumbar surgery.
There is considerable evidence that nonclinical factors, including geographic regions, type of thirdparty payers, and concentrations of physicians, impact treatment patterns and utilization of health care resources. ${ }^{5-7}$ In patients with degenerative lumbar conditions, treatments supported by varying levels of evidence are commonly applied. Physical therapy, chiropractor treatment and behavioral therapy have shown incremental improvements in treatment of back pain. ${ }^{8}$ There has been conflicting evidence on the role of lumbar ESI in alleviating pain related to lumbar degeneration. ${ }^{9,10}$ With moresevere symptoms, in appropriately selected patients, surgery has been shown to provide sustained improvement in pain and physical function. ${ }^{11,12}$ 
Table 1. ICD-9 codes and CPT codes used within analysis

\begin{tabular}{lr}
\hline Diagnosis or Treatment & Relevant ICD-9 Codes \\
\hline Lumbar degenerative conditions & ICD-9-D-7244, ICD-9-D-72252, ICD-9-D-72273, ICD-9-D-72210, ICD-9-D-72142, \\
& ICD-9-D-7213, ICD-9-D-72190, ICD-9-D-7393, ICD-9-D-72402, ICD-9-D-7384, \\
& ICD-9-D-7242, ICD-9-D-8472 \\
Lumbar degenerative conditions - steroid injection & CPT-62311, CPT-64483, CPT-64484 \\
Lumbar degenerative conditions - surgical intervention & CPT-22558, CPT-22585, CPT-22842, CPT-22843, CPT-22844, CPT-22845, CPT- \\
& 22851, CPT-22845, CPT-22612, CPT-22614, CPT-22630, CPT-22632, CPT- \\
& 22633, CPT-63005, CPT-63017, CPT-63012, CPT-63030, CPT-63042, CPT-63047 \\
\hline
\end{tabular}

Abbreviations: ICD, International Classification of Diseases; CPT, current procedural terminology.

The goals of the current study were to assess current utilization of ESIs and changes in utilization over time and to analyze the influence of payer type and geographic region within the United States on their utilization. In addition we analyzed the relationship between ESIs and surgical rates across states.

\section{MATERIALS AND METHODS}

Two national databases were used to collect information on patients with lumbar degenerative conditions. The Medicare 5\% national sample administrative database as well as one from Humana (a for-profit, publicly traded health insurance provider) were queried using software from PearlDiver (PearlDiver Technologies, Colorado Springs, Colorado). The Humana database is a collection of all health care coding over time for patients with Humana health insurance. Both the Medicare database and Humana database have been used in numerous publications. ${ }^{13-15}$ These databases are compliant with all regulations associated with the Health Insurance Portability and Accountability Act, as all patient identifiers were removed from the clinical/financial data. No Institutional Review Board authorization was required to conduct this study.

The database query began by first identifying the current procedural terminology (CPT) codes and International Classification of Diseases (ICD-9) codes relevant to our topic of interest. For lumbar degenerative conditions, we used a variety of ICD-9 codes to select patients who had ever been diagnosed with lumbar degenerative disorders. The ICD-9 codes that were used for our analysis are shown in Table 1. Similarly, relevant CPT Codes for ESIs and spinal surgery were identified and are also included in Table 1. In both the Medicare database (SAF5) and the Humana database (HORTHO), we first selected those patients with lumbar degenerative conditions. From this cohort we identified patients who had ESI and/or a lumbar surgical procedure. For patients who did have surgery, we also determined what portion of these patients had an ESI prior to their surgery.

We grouped certain states into discrete geographic regions to determine variability in rates of ESI and surgery across the United States. The South included Alabama, Arkansas, Delaware, Florida, Georgia, Kentucky, Louisiana, Maryland, Mississippi, North Carolina, Oklahoma, South Carolina, Tennessee, Texas, Virginia, and West Virginia. The Midwest included Illinois, Indiana, Iowa, Kansas, Michigan, Minnesota, Missouri, Nebraska, North Dakota, Ohio, South Dakota, and Wisconsin. The Northeast included Connecticut, Maine, Massachusetts, New Hampshire, New Jersey, New York, Pennsylvania, Rhode Island, and Vermont. The West included Alaska, Arizona, California, Colorado, Hawaii, Idaho, Montana, Nevada, New Mexico, Oregon, Utah, Washington, and Wyoming.

The costs associated with ESI in patients with lumbar degenerative conditions were aggregated to determine the financial impact of these procedures. Reimbursements from both the SAF5 and HORTHO databases were aggregated.

A Pearson chi-square test was used to compare the proportion of patients who had an ESI between both the HORTHO and SAF5 data sets. A linear regression analysis was performed to determine statistically significant linear relationships between treatment variables. Specifically, comparisons were made between the surgical rate/injection rate versus time and surgical rate versus injection rate for states.

\section{RESULTS}

Demographic information for patients included within this study from both the HORTHO database as well as the SAF5 database are shown in detail in Tables 2 and 3. There were 4108121 patients with symptomatic lumbar degenerative conditions analyzed in the current study. In both databases the 
Virk et al.

Table 2. Patient demographics for the symptomatic lumbar degeneration, surgical, and ESI cohorts from the Medicare database.

\begin{tabular}{|c|c|c|c|}
\hline Patient Characteristic & Symptomatic Lumbar Degeneration & ESI Group & Surgery Group \\
\hline \multicolumn{4}{|l|}{ Sex } \\
\hline Male & $40.32 \%(495842)$ & $37.33 \%(74138)$ & $45.30 \%(28416)$ \\
\hline Female & $59.68 \%$ (733 925) & $62.66 \%(124444)$ & $54.70 \%(34313)$ \\
\hline \multicolumn{4}{|l|}{ Age distribution } \\
\hline$<65$ & $15.51 \%$ (190 737) & $16.09 \%(31955)$ & $20.83 \%(13066)$ \\
\hline $65-69$ & $22.24 \%(273500)$ & $20.29 \%(40296)$ & $25.42 \%(15945)$ \\
\hline $70-74$ & $19.64 \%(241526)$ & $20.15 \%(40018)$ & $22.42 \%(14046)$ \\
\hline $75-79$ & $17.14 \%(210782)$ & $18.46 \%(36661)$ & $17.38 \%(10902)$ \\
\hline $80-84$ & $14.02 \%(172413)$ & $14.87 \%(29532)$ & $9.95 \%(6241)$ \\
\hline $85+$ & $11.45 \%(140808)$ & $10.14 \%\left(\begin{array}{lll}20 & 138\end{array}\right)$ & $4.00 \%(2509)$ \\
\hline \multicolumn{4}{|l|}{ Geographic region } \\
\hline Northeast & $17.97 \%$ (220 989) & $15.26 \%(30306)$ & $13.35 \%(8374)$ \\
\hline Midwest & $24.56 \%(302031)$ & $25.80 \%$ (51 239) & $24.12 \%\left(\begin{array}{lll}15 & 130\end{array}\right)$ \\
\hline South & $39.84 \%(489939)$ & $41.37 \%(82161)$ & $44.21 \%(27732)$ \\
\hline West & $17.63 \%(216808)$ & $17.57 \%(34894)$ & $18.33 \%(11498)$ \\
\hline
\end{tabular}

Abbreviation: ESI, epidural steroid injection.

majority of patients are older than 65 years, although as anticipated a larger portion of patients in the SAF5 database are older than 65 years. The South is the most-represented geographic region in both databases.

The rate of ESI per year for patients with lumbar degenerative conditions between 2007 and 2012 is shown in Table 4 and Figure 1. There is no significant change in the rate of ESI/y between 2007 and 2012 for the combined SAF5 and HORTHO databases $(P=.119)$. Our analysis also explored the variation of care based on payer type for ESI. In order to properly compare the patients from our private payer database with Medicare patients, we only included patients older than 65 for both databases for this analysis. We identified a higher rate of ESI for patients in the Medicare group compared with the private payer group for patients older than 65 years $(16.27 \%$ versus $14.14 \%$, respectively; $P<.001)$. A state-by-state breakdown of ESI rates revealed that 43 of 50 states in the United States had statistically significant higher rates of ESI in the Medicare cohort compared with the private pay cohort, as shown in Table 5. A map showing the state-by-state overall ESI rate is shown in Figure 2. A map showing the state-by-state overall lumbar surgery rate is shown in Figure 3.

The rate of lumbar surgery did not change significantly between 2007 and 2012 (Table 6 and Figure 4). Similar to ESI, considerable geographic variation in the rates of lumbar surgeries was identified (Table 7). States with the highest and lowest rates of ESI and lumbar surgery are shown in Tables $8 \mathrm{a}$ and $8 \mathrm{~b}$. Significant variation in rates of diagnosis of symptomatic lumbar degenerative conditions $(P<.001)$, surgery $(P<.001)$, and ESI $(P<.001)$ was observed between geographic regions in the United States as well (Table 9).

The rate of steroid injections and the rate of surgery were compared between states. A positive

Table 3. Patient demographics for the symptomatic lumbar degeneration, surgical, and ESI cohorts from the HORTHO database.

\begin{tabular}{|c|c|c|c|}
\hline Patient Characteristic & Symptomatic Lumbar Degeneration & ESI Group & Surgery Group \\
\hline \multicolumn{4}{|l|}{ Sex } \\
\hline Male & $42.32 \%\left(\begin{array}{llll}1 & 218 & 119\end{array}\right)$ & $40.63 \%(149300)$ & $48.72 \%(63922)$ \\
\hline Female & $57.68 \%\left(\begin{array}{lll}1 & 660 & 234\end{array}\right)$ & $59.37 \%(218163)$ & $51.28 \%(67281)$ \\
\hline \multicolumn{4}{|l|}{ Age distribution } \\
\hline$<60$ & $33.79 \%(972595)$ & $26.86 \%(98700)$ & $31.77 \%\left(\begin{array}{ll}41 & 683\end{array}\right)$ \\
\hline $60-64$ & $8.23 \%(236888)$ & $9.16 \%(33659)$ & $10.37 \%(13605)$ \\
\hline $65-69$ & $17.45 \%(502272)$ & $18.02 \%(66217)$ & $20.21 \%(26516)$ \\
\hline $70-74$ & $15.63 \%(449886)$ & $17.61 \%(64710)$ & $18.38 \%\left(\begin{array}{ll}24 & 115\end{array}\right)$ \\
\hline $75-79$ & $11.31 \%(325541)$ & $13.38 \%(49166)$ & $11.42 \%(14983)$ \\
\hline $80-84$ & $7.48 \%(215300)$ & $8.82 \%(32410)$ & $5.53 \%(7255)$ \\
\hline $85+$ & $6.11 \%(175867)$ & $6.16 \%(22635)$ & $2.32 \%(3043)$ \\
\hline \multicolumn{4}{|l|}{ Geographic region } \\
\hline Northeast & $2.09 \%(60157)$ & $2.06 \%(7569)$ & $1.99 \%(2610)$ \\
\hline Midwest & $24.87 \%(715846)$ & $26.39 \%(96973)$ & $25.25 \%(33129)$ \\
\hline South & $63.43 \%(1825739)$ & $61.27 \%(225145)$ & $62.69 \%(82251)$ \\
\hline West & $9.61 \%(276609)$ & $10.29 \%(37812)$ & $10.07 \%\left(\begin{array}{ll}13 & 212\end{array}\right)$ \\
\hline
\end{tabular}

Abbreviations: ESI, epidural steroid injection; HORTHO, Humana orthopaedic database. 
Table 4. The combined rate of ESI for 2007 to 2012 for patients diagnosed with back pain. The rate of ESI is based on the total number of patients treated with ESI divided by the number of patients with lumbar degenerative conditions over the same period.

\begin{tabular}{lc}
\hline Year & $\begin{array}{c}\text { Rate of ESI for Patients With Lumbar } \\
\text { Degenerative Conditions per Year, \% }\end{array}$ \\
\hline 2007 & 9.84 \\
2008 & 9.98 \\
2009 & 10.11 \\
2010 & 10.17 \\
2011 & 10.18 \\
2012 & 10.05 \\
\hline
\end{tabular}

Abbreviation: ESI, epidural steroid injection.

correlation between rates of ESI and lumbar surgery was identified $(P=.001)$ (Table 7 and Figure 5A). A similar analysis was performed isolating only those patients older than 65 years within the HORTHO and SAF5 databases (Figure 5B). As with the general population, the rate of injections did correlate positively with the rate of surgery across states for the elderly $(P<.0001)$.

A breakout analysis was performed on the rate of ESI in patients who undergo surgery in the private payer and the Medicare cohorts. Once again, when comparing these 2 databases, we only included those patients who were older than 65 years. There was a higher rate of ESI for patients who eventually underwent surgery in the Medicare group as compared with the commercial payer group (55.30\% versus $40.40 \%, P<.001)$.

The average Medicare reimbursement for ESI (\$635 $\pm \$ 32)$ was significantly higher than for the private payer cohort $(\$ 524 \pm \$ 74)(P=.03)$.

\section{DISCUSSION}

The current study identifies that geography and the type of third party payer all factor in the

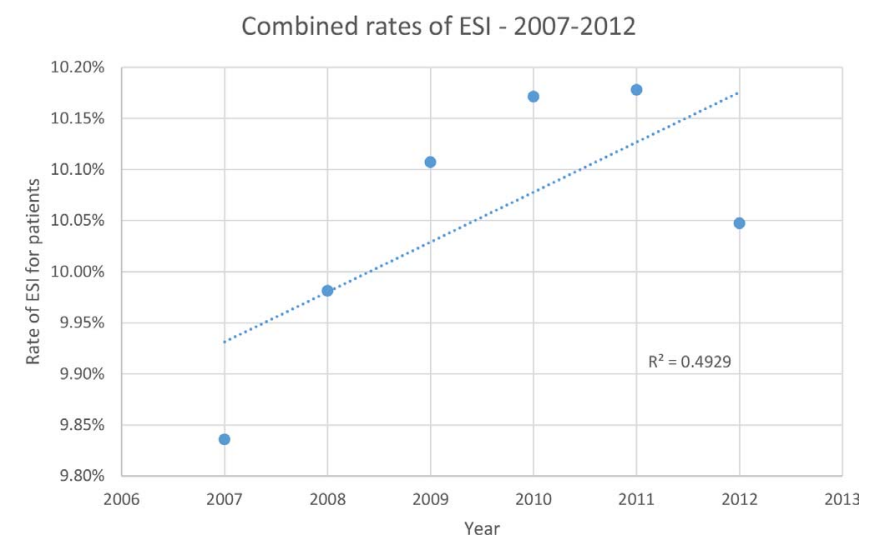

Figure 1. Rate of epidural steroid injection over time combining both the Humana and Medicare databases $(P=.119)$. Abbreviation: ESI, epidural steroid injection.

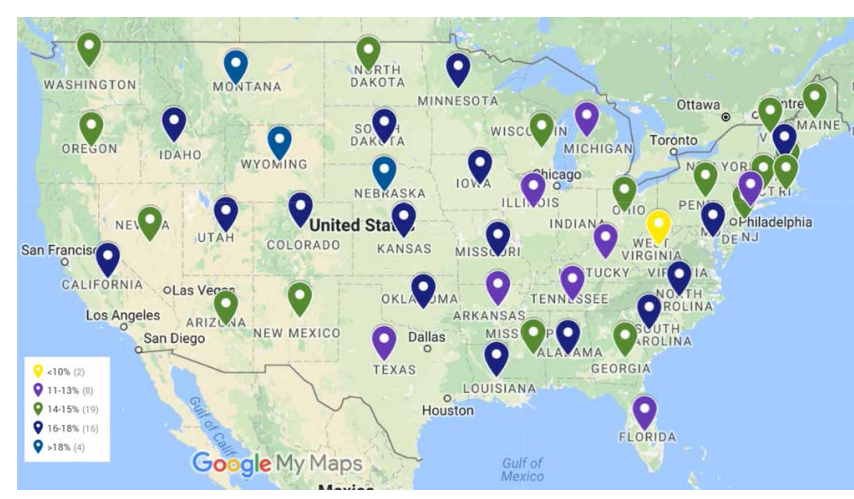

Figure 2. Map of lumbar epidural steroid injection rates.

utilization of ESIs for lumbar degenerative conditions. From 2007 to 2012 there was no statistically significant change in the rate of ESI nor the rate of surgery for patients with lumbar degenerative conditions. These rates of ESI and surgery never varied more than a percentage point. We also identified a significant variation in utilization of ESIs across geographic regions. Isolating the effect of payer characteristic, there is a significantly higher rate of lumbar ESI for patients with Medicare as compared with a commercial insurance company. Our state-by-state analysis demonstrated an association between higher rates of ESI and higher rates of surgery.

There has been conflicting evidence on the role of ESI in alleviating radicular or neurogenic pain. ${ }^{9,10}$ During the period 1994-2001, there was a $271 \%$ increase in the number of ESI procedures. ${ }^{16}$ The current study shows the use of ESI in patients with symptomatic lumbar degenerative conditions largely leveled off between the years 2007 and 2012 for both Medicare and private insurance patients. During this same period, ESIs have come under increasing scrutiny, and narrow guidelines for their indications have been proposed. For instance, the North

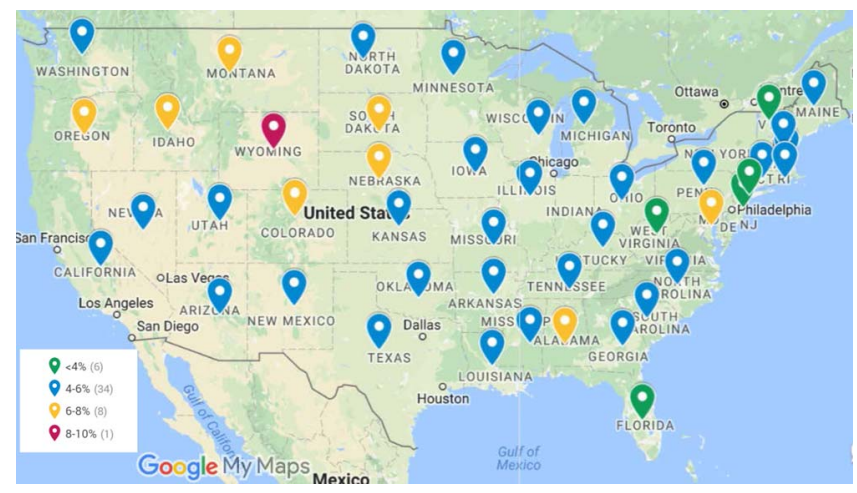

Figure 3. Map of lumbar surgery rates. 
Table 5. Rate of ESI for elderly patients. All $P$ values in bold are significant.

\begin{tabular}{|c|c|c|c|c|c|c|c|}
\hline State & $\begin{array}{c}\text { Medicare 5\%- } \\
\text { ESI Patients }\end{array}$ & $\begin{array}{c}\text { Medicare 5\%- } \\
\text { Back Pain } \\
\text { Patients } \\
\end{array}$ & $\begin{array}{l}\text { Medicare 5\% } \\
\text { Database, \% } \\
\end{array}$ & $\begin{array}{c}\text { Humana- } \\
\text { ESI Patients }\end{array}$ & $\begin{array}{c}\text { Humana- } \\
\text { Back Pain Patients }\end{array}$ & $\begin{array}{c}\text { Private Payer } \\
\text { Database, \% }\end{array}$ & $P$ Value \\
\hline Alaska & 219 & 1514 & 14.46 & 42 & 317 & 13.25 & 0.32 \\
\hline Alabama & 4699 & 25384 & 18.51 & 3457 & 22484 & 15.38 & $3.52 \mathrm{E}-47$ \\
\hline Arkansas & 1696 & 12418 & 13.66 & 2358 & 21589 & 10.92 & $9.76 \mathrm{E}-58$ \\
\hline Arizona & 3685 & 21547 & 17.10 & 5820 & 38262 & 15.21 & $1.84 \mathrm{E}-15$ \\
\hline California & 14434 & 89528 & 16.12 & 3483 & 25524 & 13.65 & $1.46 \mathrm{E}-24$ \\
\hline Colorado & 2892 & 13777 & 20.99 & 4138 & 22318 & 18.54 & 2.79E-113 \\
\hline Connecticut & 2104 & 14779 & 14.24 & 167 & 1097 & 15.22 & 0.014 \\
\hline Delaware & 625 & 4358 & 14.34 & 155 & 1107 & 14.00 & 0.15 \\
\hline Florida & 14289 & 84553 & 16.90 & 39037 & 330289 & 11.82 & 0 \\
\hline Georgia & 5766 & 34165 & 16.88 & 8407 & 55901 & 15.04 & $7.72 E-19$ \\
\hline Hawaii & 238 & 3084 & 7.72 & 290 & 4246 & 6.83 & 5.32E-67 \\
\hline Idaho & 1003 & 5294 & 18.95 & 1290 & 9454 & 13.65 & $3.98 \mathrm{E}-16$ \\
\hline Illinois & 8356 & 49796 & 16.78 & 8187 & 57148 & 14.33 & $3.50 \mathrm{E}-28$ \\
\hline Indiana & 6172 & 26118 & 23.63 & 8479 & 42334 & 20.03 & $\mathbf{0}$ \\
\hline Iowa & 2662 & 15614 & 17.05 & 2648 & 17752 & 14.92 & $5.55 \mathrm{E}-11$ \\
\hline Kansas & 3299 & 16183 & 20.39 & 3677 & 19840 & 18.53 & $5.40 \mathrm{E}-105$ \\
\hline Kentucky & 2615 & 20603 & 12.69 & 9641 & 73870 & 13.05 & $1.69 \mathrm{E}-59$ \\
\hline Louisiana & 2660 & 14958 & 17.78 & 15294 & 76832 & 19.91 & $3.13 E-284$ \\
\hline Massachusetts & 3411 & 23376 & 14.59 & 438 & 3072 & 14.26 & 0.044 \\
\hline Maryland & 4339 & 27419 & 15.82 & 252 & 1675 & 15.04 & $5.70 \mathrm{E}-4$ \\
\hline Maine & 826 & 6015 & 13.73 & 241 & 2173 & 11.09 & 7.42E-08 \\
\hline Michigan & 5464 & 42207 & 12.95 & 4152 & 36634 & 11.33 & $2.68 \mathrm{E}-100$ \\
\hline Minnesota & 3161 & 17919 & 17.64 & 3618 & 25808 & 14.02 & $2.29 \mathrm{E}-23$ \\
\hline Mississippi & 1975 & 11356 & 17.39 & 3203 & 20643 & 15.52 & $1.19 \mathrm{E}-11$ \\
\hline Missouri & 5349 & 29137 & 18.36 & 6930 & 41314 & 16.77 & $1.88 \mathrm{E}-67$ \\
\hline Montana & 947 & 4493 & 21.08 & 1564 & 8852 & 17.67 & 9.51E-35 \\
\hline North Carolina & 7538 & 45293 & 16.64 & 9952 & 65983 & 15.08 & $4.29 \mathrm{E}-19$ \\
\hline North Dakota & 633 & 4215 & 15.02 & 367 & 2954 & 12.42 & 2.73E-4 \\
\hline Nebraska & 1784 & 8530 & 20.91 & 936 & 6105 & 15.33 & $6.23 \mathrm{E}-45$ \\
\hline New Hampshire & 984 & 5880 & 16.73 & 216 & 1637 & 13.19 & $9.90 \mathrm{E}-05$ \\
\hline New Jersey & 6099 & 46550 & 13.10 & 259 & 2080 & 12.45 & $1.40 \mathrm{E}-28$ \\
\hline New Mexico & 929 & 6079 & 15.28 & 1005 & 8434 & 11.92 & $1.68 \mathrm{E}-13$ \\
\hline Nevada & 1257 & 6941 & 18.11 & 3250 & 27049 & 12.02 & $7.49 \mathrm{E}-47$ \\
\hline New York & 7339 & 61422 & 11.95 & 913 & 8427 & 10.83 & 3.28E-107 \\
\hline Ohio & 7496 & 50406 & 14.87 & 17283 & 127035 & 13.60 & $8.24 E-39$ \\
\hline Oklahoma & 2808 & 15395 & 18.24 & 2421 & 16046 & 15.09 & $6.01 \mathrm{E}-25$ \\
\hline Oregon & 1737 & 11797 & 14.72 & 391 & 3256 & 12.01 & $6.53 \mathrm{E}-06$ \\
\hline Pennsylvania & 7781 & 49640 & 15.67 & 3341 & 24912 & 13.41 & $4.15 \mathrm{E}-14$ \\
\hline Rhode Island & 449 & 3151 & 14.25 & 40 & 326 & 12.27 & 0.089 \\
\hline South Carolina & 3849 & 18807 & 20.47 & 6395 & 38568 & 16.58 & $1.93 E-96$ \\
\hline South Dakota & 966 & 5006 & 19.30 & 829 & 5684 & 14.58 & $3.96 \mathrm{E}-15$ \\
\hline Tennessee & 4159 & 27118 & 15.34 & 8007 & 65335 & 12.26 & $1.28 \mathrm{E}-74$ \\
\hline Texas & 13009 & 74911 & 17.37 & 19535 & 132677 & 14.72 & $2.13 E-63$ \\
\hline Utah & 1639 & 6921 & 23.68 & 3072 & 15207 & 20.20 & $2.26 \mathrm{E}-136$ \\
\hline Virginia & 5071 & 30222 & 16.78 & 7506 & 56917 & 13.19 & $4.24 \mathrm{E}-43$ \\
\hline Vermont & 399 & 2791 & 14.30 & 67 & 524 & 12.79 & 0.099 \\
\hline Washington & 3640 & 22718 & 16.02 & 2193 & 18473 & 11.87 & $1.15 E-31$ \\
\hline Wisconsin & 3833 & 21138 & 18.13 & 7738 & 46177 & 16.76 & $7.77 \mathrm{E}-52$ \\
\hline West Virginia & 900 & 9106 & 9.88 & 2773 & 31421 & 8.83 & $2.72 \mathrm{E}-211$ \\
\hline Wyoming & 481 & 2277 & 21.12 & 295 & 1611 & 18.31 & $1.51 \mathrm{E}-16$ \\
\hline
\end{tabular}

Abbreviation: ESI, epidural steroid injection.

American Spine Society has set guidelines for lumbar transforaminal epidural steroid injections, including their limited use for patients with sciatica with displaced or entrapped disc herniations. ${ }^{17}$ Given these narrow indications, it is not surprising that the rate of ESI has largely remained stable.

As with the rates of ESI, surgical rates for patients with lumbar degenerative conditions have remained relatively consistent between 2007 and 2012 at approximately $2 \%$ to $3 \%$. Note that this yearly rate is smaller than the geographic rates mentioned due to the fact that there is a discrete time period in which patients with lumbar degenerative conditions may be treated with surgery. This has occurred during a time when there have been significant increases in total amounts spent on treatment for low back pain. ${ }^{18}$ An overwhelming majority of the increases in costs are associated with use of nonsurgical treatments such as the use of opioids, magnetic resonance imaging, and ESIs. ${ }^{19,20}$ Previous research has suggested that despite these added costs, the burden of low back pain has remained substantial. ${ }^{21}$ 
Table 6. The combined rate of lumbar surgery from 2007 to 2012 for patients diagnosed with back pain. The rate of surgery is based on the total number of patients treated with a lumbar surgery divided by the number of patients with lumbar degenerative conditions over the same period.

\begin{tabular}{lc}
\hline Year & $\begin{array}{r}\text { Rate of Lumbar Surgery for Patients With Lumbar } \\
\text { Degenerative Conditions per Year, \% }\end{array}$ \\
\hline 2007 & 2.32 \\
2008 & 2.36 \\
2009 & 2.47 \\
2010 & 2.52 \\
2011 & 2.45 \\
2012 & 2.48 \\
\hline
\end{tabular}

Combined Yearly Rates of Surgery - 2007-2012

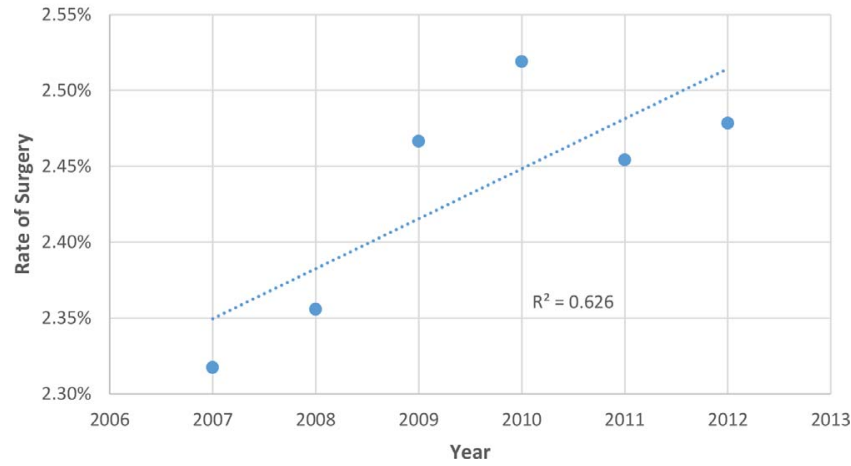

Figure 4. There is no significant increase/decrease in the rate of surgery between the years 2007 and 2012 for patients with back pain $(P=.061)$.

Table 7. Combined rates of surgery and epidural steroid injectionacross states.

\begin{tabular}{|c|c|c|c|c|c|}
\hline State & Total Surgical Patients & Total Injection Patients & Total Back Pain Patients & Rate of Surgery, \% & Rate of Injections, \% \\
\hline Alaska & 164 & 326 & 2238 & 7.33 & 14.57 \\
\hline Alabama & 4341 & 12354 & 71319 & 6.09 & 17.32 \\
\hline Arkansas & 2517 & 6093 & 49352 & 5.10 & 12.35 \\
\hline Arizona & 3872 & 13251 & 92519 & 4.19 & 14.32 \\
\hline California & 6194 & 21248 & 140949 & 4.39 & 15.07 \\
\hline Colorado & 4320 & 10306 & 62449 & 6.92 & 16.50 \\
\hline Connecticut & 833 & 2610 & 18507 & 4.50 & 14.10 \\
\hline Delaware & 310 & 946 & 6479 & 4.78 & 14.60 \\
\hline Florida & 22950 & 77713 & 652130 & 3.52 & 11.92 \\
\hline Georgia & 10078 & 25847 & 189231 & 5.33 & 13.66 \\
\hline Hawaii & 230 & 608 & 8333 & 2.76 & 7.30 \\
\hline Idaho & 1274 & 2763 & 17801 & 7.16 & 15.52 \\
\hline Illinois & 7656 & 24008 & 184774 & 4.14 & 12.99 \\
\hline Indiana & 5704 & 20262 & 107111 & 5.33 & 18.92 \\
\hline Iowa & 1827 & 6127 & 38905 & 4.70 & 15.75 \\
\hline Kansas & 2835 & 9335 & 56943 & 4.98 & 16.39 \\
\hline Kentucky & 8985 & 21530 & 191854 & 4.68 & 11.22 \\
\hline Louisiana & 8311 & 25770 & 146038 & 5.69 & 17.65 \\
\hline Massachusetts & 1557 & 4741 & 33077 & 4.71 & 14.33 \\
\hline Maryland & 2279 & 5343 & 33699 & 6.76 & 15.86 \\
\hline Maine & 478 & 1378 & 10478 & 4.56 & 13.15 \\
\hline Michigan & 5602 & 13454 & 116030 & 4.83 & 11.60 \\
\hline Minnesota & 2531 & 7881 & 51187 & 4.94 & 15.40 \\
\hline Mississippi & 2940 & 8456 & 56391 & 5.21 & 15.00 \\
\hline Missouri & 5440 & 16882 & 105665 & 5.15 & 15.98 \\
\hline Montana & 1082 & 2860 & 15538 & 6.96 & 18.41 \\
\hline North Carolina & 8183 & 23918 & 148181 & 5.52 & 16.14 \\
\hline North Dakota & 382 & 1129 & 8148 & 4.69 & 13.86 \\
\hline Nebraska & 1119 & 3254 & 17725 & 6.31 & 18.36 \\
\hline New Hampshire & 403 & 1487 & 9272 & 4.35 & 16.04 \\
\hline New Jersey & 1662 & 7481 & 57379 & 2.90 & 13.04 \\
\hline New Mexico & 848 & 2515 & 18778 & 4.52 & 13.39 \\
\hline Nevada & 2128 & 5915 & 43829 & 4.86 & 13.50 \\
\hline New York & 2967 & 10027 & 85927 & 3.45 & 11.67 \\
\hline Ohio & 11169 & 32212 & 238021 & 4.69 & 13.53 \\
\hline Oklahoma & 2569 & 7415 & 43109 & 5.96 & 17.20 \\
\hline Oregon & 1377 & 2570 & 18781 & 7.33 & 13.68 \\
\hline Pennsylvania & 4601 & 13690 & 92771 & 4.96 & 14.76 \\
\hline Rhode Island & 217 & 667 & 4531 & 4.79 & 14.72 \\
\hline South Carolina & 4602 & 14191 & 79358 & 5.80 & 17.88 \\
\hline South Dakota & 855 & 2013 & 12134 & 7.05 & 16.59 \\
\hline Tennessee & 8398 & 18359 & 149278 & 5.63 & 12.30 \\
\hline Texas & 21306 & 52797 & 411701 & 5.18 & 12.82 \\
\hline Utah & 1881 & 6223 & 34978 & 5.38 & 17.79 \\
\hline Virginia & 6325 & 17013 & 117044 & 5.40 & 14.54 \\
\hline Vermont & 150 & 546 & 4022 & 3.73 & 13.58 \\
\hline Washington & 2754 & 7039 & 51012 & 5.40 & 13.80 \\
\hline Wisconsin & 5343 & 17456 & 124546 & 4.29 & 14.02 \\
\hline West Virginia & 2035 & 4828 & 51828 & 3.93 & 9.32 \\
\hline Wyoming & 439 & 899 & 4547 & 9.65 & 19.77 \\
\hline
\end{tabular}


Table 8a. States with the 5 highest and lowest rates for ESI.

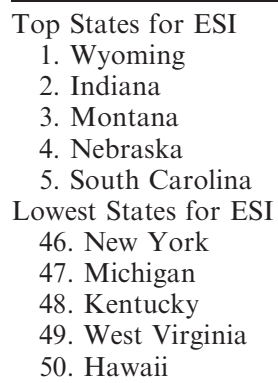

Abbreviation: ESI, epidural steroid injection.

Prior studies have suggested that variations in treatment based on payer type may relate in part to lower physician reimbursement rates from Medicare. ${ }^{22}$ The effect of payments on care is obviously complex and may be more nuanced than the dollar amount reimbursed. For example, there is evidence that reduced payment delays for Medicare-related services increase physician treatment of Medicare patients. ${ }^{23}$ The influence of payer type is not always consistent, and there is conflicting evidence on the impact of insurance carrier on treatment patterns. ${ }^{24}$ In the current study, Medicare patients had a higher rate of ESIs than age-matched patients with private insurance. The reasons for this are unclear but may reflect different patient expectations given that those covered by Medicare are more likely to have exited the workforce. The type of payer may also affect the type of physician exposure, with certain specialists perhaps more likely to limit access to Medicare patients, resulting in different treatment patterns based on physicians' specialty or training. Treatment decisions may also be the result of differing financial incentives for alternate treatments based on payer status. In addition, despite studies confirming good surgical results in selected patients with lumbar degenerative conditions, ${ }^{25-27}$ during the time period of the current study there has been aggressive private payer pushback against spinal surgery, resulting in surgery being denied or delayed. Clearly, further research is required to understand why Medicare patients are more often funneled towards ESI for treatment of lumbar degenerative conditions across the country. The data point to nonclinical factors influencing the treatment pathway for patients with this diagnosis.

Geographic variation in care has been well documented. ${ }^{5,28,29}$ Fisher et al ${ }^{30}$ showed that Medicare enrollees in higher-spending regions received significantly more end-of-life care than lower-spend-
Table 8b. States with the 5 highest and lowest rates of surgery.

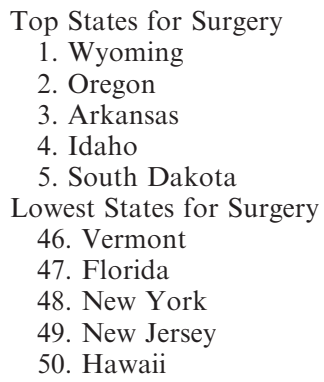

ing geographic regions. The current study identified variations in rate of lumbar ESI between states and across geographic regions. The authors acknowledge that in some instances these differences in ESI may be small, as with Pennslyvania (14.76\%) and Rhode Island (14.72\%). Still, the rates of ESI in other areas of the country did show large variations, as were found between Alabama (17.32\%) and Arkansas $(14.57 \%)$. The reason for these differences can be difficult to explain by clinical factors alone. Importantly, the study confirmed an association between higher rates of ESIs and higher rates of surgery, with states generally having consistently high or low rates of both surgery and ESI. Rates of both ESI and lumbar surgery were higher in more-rural states. Interestingly, Wyoming was a significant outlier, with rates of ESIs and surgery of $19.77 \%$ and $9.65 \%$, respectively. This can be compared with Hawaii, where rates for ESIs and surgery were $7.30 \%$ and $2.76 \%$, respectively. Furthermore, these states have similar populations of lumbar degenerative changes (both have fewer than 10000 patients with lumbar degenerative conditions). The reason for this large disparity warrants further investigation. Our data further suggest that increased use of ESIs does not correspond to any reduction in the rates of lumbar surgery. In fact, the data confirm that certain states consume greater resources, with higher rates of both non-surgical and surgical resources for the treatment of patients with lumbar degenerative conditions. Whether this higher utilization of resources translates into improved clinical outcomes and provides value or is reflective of overutilization remains to be determined.

In both the private payer and Medicare cohorts who eventually went on to surgery, more than $50 \%$ had received an ESI as a part of their treatment. In the Medicare cohort a higher proportion of patients had received an ESI prior to surgery than the private payer cohort. The effectiveness of ESI for 

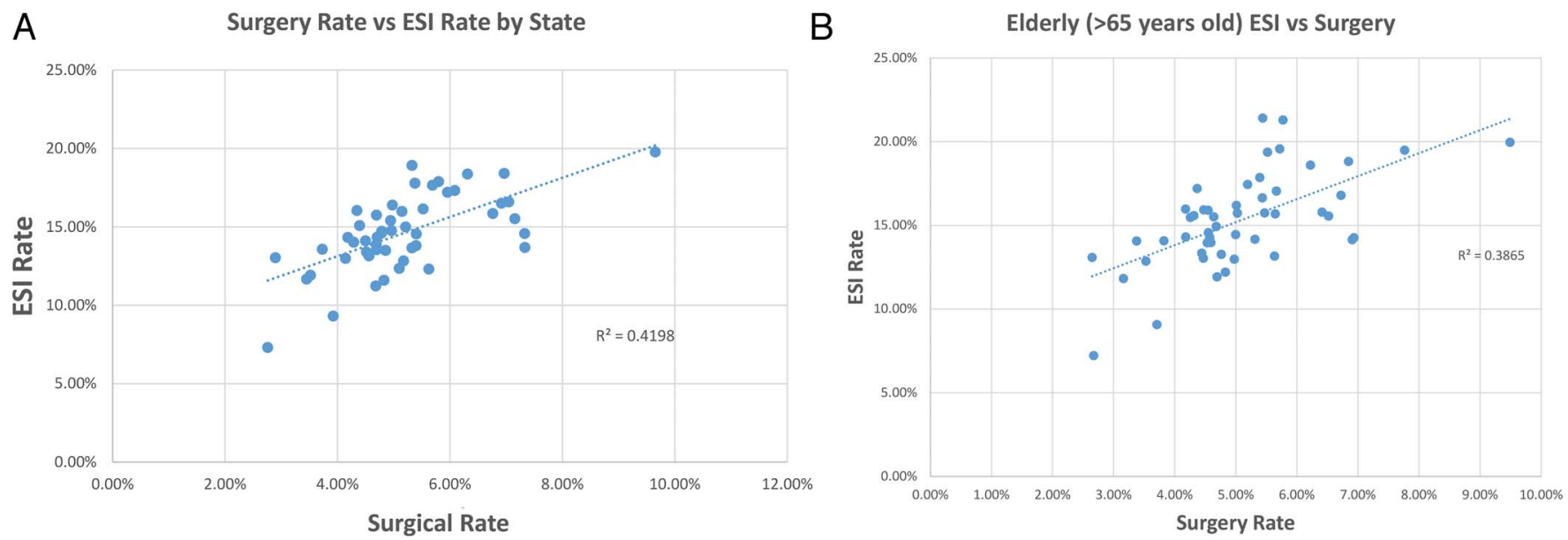

Figure 5. (A) There is a positive correlation between the rate of injections and the rate of surgery for all states. The $P$ value for this correlation is less than .0001. (B) As with the general population, there is a positive correlation between the rate of epidural steroid injection (ESI) and rate of surgery among patients older than 65 years. The $P$ value of this correlation is less than .0001 .

the treatment of sciatica and neurogenic claudication has come under scrutiny. ${ }^{18,31}$ Furthermore, the role of ESI in patients who eventually undergo lumbar surgery is unclear, and recent studies on patients with spinal stenosis have suggested a negative effect on outcomes. ${ }^{32}$ Further research is required to define the value added and/or costeffectiveness of ESI for patients eventually requiring surgery. The authors acknowledge that a portion of third-party payers may only approve coverage of lumbar surgery when nonoperative treatments such as ESI are provided for patients.

There are several limitations to this study. As with other large database studies that rely on physician/hospital billing of CPT, ICD-9, and diagnosis related groups (DRG) codes, there are weaknesses associated with discrepancies between claims databases and patient chart reviews. ${ }^{33}$ Physicians and hospitals that bill frequently do, however, have a vested interest in accurately billing CPT, ICD-9, and DRG codes in order to avoid fraud and to be properly reimbursed. Although the authors attempted to eliminate age as a confounding factor between the commercial payer and Medicare groups, there may be inherent differences in the health of patients using Medicare as compared with patients with commercial insurance. As shown in Tables 3 and 4, the geographic distribution of patients is not even. This is especially pronounced for the Humana data set, with the South representing more than $60 \%$ of patients. The authors acknowledge this as a source of geographic bias within our study. We also acknowledge that we do not know how the rate of diagnosis of lumbar degenerative conditions varies across states. This may significantly affect comparisons of rates of ESI/ surgery in different parts of the country. Similarly, we do not know how closely physicians adhere to national guidelines for treatment of ESI or have validated indications for lumbar surgery across the country. Furthermore, it is impossible to determine the clinical indications for individual patients in regard to ESIs and lumbar surgery based on CPT, ICD-9, and DRG codes alone.

In summary, there is significant variation in utilization of ESIs that is not explained by clinical patient factors alone. Other factors include the geographic location of the patient as well as the type of insurance a patient carries. The data suggest that during the five years of the study, rates of surgical treatment for lumbar degenerative conditions have remained consistent. The data also suggest a

Table 9. Breakdown of the rate of ESI and surgery among geographic regions. These figures represent cumulative rates of surgery or ESI for patients with back pain over multiple years (2007-2012).

\begin{tabular}{lcc}
\hline Region & $\begin{array}{c}\text { Rate of ESI for Patients With Lumbar } \\
\text { Degenerative Conditions During 2007-2012 }\end{array}$ & $\begin{array}{c}\text { Rate of Surgery for Patients With Lumbar } \\
\text { Degenerative Conditions During 2007 and 2012 }\end{array}$ \\
\hline Midwest & $14.51 \%(596088)$ & $4.76 \%(195546)$ \\
Northeast & $13.49 \%(554185)$ & $4.07 \%(167200)$ \\
South & $13.33 \%(547612)$ & $4.84 \%(198833)$ \\
West & $15.25 \%(626488)$ & $5.29 \%(217319)$
\end{tabular}

Abbreviation: ESI, epidural steroid injection. 
positive correlation between rates of ESIs and surgical intervention across states. This points to areas in the country with high utilization of both ESI and surgery in the treatment of this diagnosis.

\section{REFERENCES}

1. Staal JB, de Bie R, de Vet HC, et al. Injection therapy for subacute and chronic low-back pain. Cochrane Database Syst Rev. 2008;00(3):Cd001824.

2. Young IA, Hyman GS, Packia-Raj LN, et al. The use of lumbar epidural/transforaminal steroids for managing spinal disease. J Am Acad Orthop Surg. 2007;15(4):228-238.

3. Kaye AD, Manchikanti L, Abdi S, et al. Efficacy of epidural injections in managing chronic spinal pain: a best evidence synthesis. Pain Physician. 2015;18(6):E939-E1004.

4. MacVicar J, King W, Landers $\mathbf{M H}$, et al. The effectiveness of lumbar transforaminal injection of steroids: a comprehensive review with systematic analysis of the published data. Pain Med. 2013;14(1):14-28.

5. Pransky G, Foley G, Cifuentes M, et al. Geographic variation in early MRI for acute work-related low back pain and associated factors. Spine (Phila Pa 1976). 2015;40(21):1712-1718.

6. Tabaraee E, Ahn J, Bohl DD, et al. The impact of worker's compensation claims on outcomes and costs following an anterior cervical discectomy and fusion. Spine (Phila Pa 1976). 2015;40(12):948-953.

7. Ugiliweneza B, Kong M, Nosova K, et al. Spinal surgery: variations in health care costs and implications for episode-based bundled payments. Spine (Phila Pa 1976). 2014;39(15):1235-1242.

8. Cherkin DC, Deyo RA, Battié M, et al. A comparison of physical therapy, chiropractic manipulation, and provision of an educational booklet for the treatment of patients with low back pain. N Engl J Med. 1998;339(15):1021-1029.

9. Cannon DT, Aprill CN. Lumbosacral epidural steroid injections. Arch Phys Med Rehabil. 2000;81(3 suppl 1):S87-S98.

10. Friedly JL, Comstock BA, Turner JA, et al. A randomized trial of epidural glucocorticoid injections for spinal stenosis. N Engl J Med. 2014;371(1):11-21.

11. Weinstein JN, Lurie JD, Tosteson TD, et al. Surgical compared with nonoperative treatment for lumbar degenerative spondylolisthesis. Four-year results in the Spine Patient Outcomes Research Trial (SPORT) randomized and observational cohorts. J Bone Joint Surg Am. 2009;91(6):1295-1304.

12. Kovacs FM, Urrutia G, Alarcon JD. Surgery versus conservative treatment for symptomatic lumbar spinal stenosis: a systematic review of randomized controlled trials. Spine (Phila Pa 1976). 2011;36(20):E1335-E1351.

13. Schoell K, Buser Z, Jakoi A, et al. Postoperative complications in patients undergoing minimally invasive sacroiliac fusion. Spine J. 2016;16(11):1324-1332.

14. Virk SS, Phillips FM, Khan SN. Reimbursement related to a 90-day episode of care for a one or two-level anterior cervical discectomy and fusion. J Bone Joint Surg Am. 2016;98(16):1378-1384.

15. Bedard NA, Dowdle SB, Anthony CA, et al. The AAHKS Clinical Research Award: what are the costs of knee osteoarthritis in the year prior to total knee arthroplasty? $J$ Arthroplasty. 2017;18(9S):S8-S10.e1

16. Friedly J, Chan L, Deyo R. Increases in lumbosacral injections in the Medicare population: 1994 to 2001. Spine (Phila Pa 1976). 2007;32(16):1754-1760.

17. Akuthota V, Bogduk N, Easa J, et al. Lumbar Transforaminal Epidural Steroid Injections: Review and Recommendation Statement. North American Spine Society; 2013. https:// www.spine.org/Documents/ResearchClinicalCare/LTFESI ReviewRecStatement.pdf. Accessed April 25, 2018.

18. Deyo RA, Mirza SK, Turner JA, et al. Overtreating chronic back pain: time to back off? JABFM. 2009;22(1):62-68.

19. Gore M, Sadosky A, Stacey BR, et al. The burden of chronic low back pain: clinical comorbidities, treatment patterns, and health care costs in usual care settings. Spine. 2012;37(11):E668-E677.

20. Wieser S, Horisberger B, Schmidhauser S, et al. Cost of low back pain in Switzerland in 2005. Eur J Health Econ. 2011;12(5):455-467.

21. Murray CJ, Atkinson C, Bhalla K, et al. The state of US health, 1990-2010: burden of diseases, injuries, and risk factors. JAMA. 2013;310(6):591-608.

22. Zuckerman JD, Koli EN, Inneh I, et al. Can a hip and knee adult reconstruction orthopaedic surgeon sustain a practice comprised entirely of Medicare patients? J Arthroplasty. 2014;29(9 suppl):132-134.

23. Cunningham PJ, O'Malley AS. Do reimbursement delays discourage Medicaid participation by physicians? Health Aff. 2009;28(1):w17-w28.

24. Doukky R, Hayes $\mathrm{K}$, Frogge $\mathrm{N}$, et al. Impact of insurance carrier, prior authorization, and socioeconomic status on appropriate use of SPECT myocardial perfusion imaging in private community-based office practice. Clin Cardiol. 2015;38(5):267-273.

25. Atlas SJ, Keller RB, Wu YA, et al. Long-term outcomes of surgical and nonsurgical management of lumbar spinal stenosis: 8 to 10 year results from the Maine Lumbar Spine Study. Spine (Phila Pa 1976). 2005;30(8):936-943.

26. Tosteson AN, Tosteson TD, Lurie JD, et al. Comparative effectiveness evidence from the Spine Patient Outcomes Research Trial: surgical versus nonoperative care for spinal stenosis, degenerative spondylolisthesis, and intervertebral disc herniation. Spine (Phila Pa 1976). 2011;36(24):2061-2068.

27. Rihn JA, Hilibrand AS, Zhao W, et al. Effectiveness of surgery for lumbar stenosis and degenerative spondylolisthesis in the octogenarian population: analysis of the Spine Patient Outcomes Research Trial (SPORT) data. J Bone Joint Surg Am. 2015;97(3):177-185.

28. Fisher ES, Bynum JP, Skinner JS. Slowing the growth of health care costs-lessons from regional variation. $N$ Engl J Med. 2009;360(9):849-852.

29. Reschovsky JD, Hadley J, O’Malley AJ, et al. Geographic variations in the cost of treating condition-specific episodes of care among Medicare patients. Health Serv Res. 2014;49(1):32-51.

30. Fisher ES, Wennberg DE, Stukel TA, et al. The implications of regional variations in Medicare spending. Part 2: health outcomes and satisfaction with care. Ann Intern Med. 2003;138(4):288-298.

31. Carette S, Leclaire R, Marcoux S, et al. Epidural 
corticosteroid injections for sciatica due to herniated nucleus pulposus. N Engl J Med. 1997;336(23):1634-1640.

32. Radcliff K, Kepler C, Hilibrand A, et al. Epidural steroid injections are associated with less improvement in patients with lumbar spinal stenosis: a subgroup analysis of the Spine Patient Outcomes Research Trial. Spine (Phila Pa 1976). 2013;38(4):279-291.

33. Bozic KJ, Chiu VW, Takemoto SK, et al. The validity of using administrative claims data in total joint arthroplasty outcomes research. J Arthroplasty. 2010;25(6 suppl):58-61.

Disclosures and COI: The authors received no funding for this study and report no conflicts of interest.
Corresponding Author: Safdar N. Khan, MD, Department of Orthopaedics, The Ohio State University, 725 Prior Hall, Columbus, OH 43210. Phone: (614) 293-2165; Fax: (614) 293-4755; Email: safdar.khan@osumc.edu.

Published 3 August 2018

This manuscript is generously published free of charge by ISASS, the International Society for the Advancement of Spine Surgery. Copyright (C) 2018 ISASS. To see more or order reprints or permissions, see http://ijssurgery.com. 